\title{
Geografia e turismo: caminhos e desafios para a complexa leitura do patrimônio de Garopaba (SC)
}

\section{Geography and tourism: paths and challenges for a complex reading of patrimony at Garopaba (SC, Brazil)}

\author{
Juliane Magagnin da Soller, Antonio Carlos Castrogiovanni
}

\begin{abstract}
RESUMO
O texto traz a pesquisa cujo objetivo central foi estudar a relação do turismo com a geografia, considerando o papel do ensino de geografia na leitura do patrimônio local. Ambientado em Garopaba, município litorâneo do estado de Santa Catarina, buscamos conhecer, provisoriamente, a importância do ensino de geografia na construção do espaço turístico, sendo que para sua compreensão empregamos na pesquisa os conceitos geográficos e a teoria das representações sociais contidas na leitura da paisagem e na construção do lugar. O método empregado foi o do paradigma da complexidade. Com a metodologia da pesquisa qualitativa, realizamos entrevistas episódicas com sujeitos turistas, moradores, professores de geografia locais e sujeitos que não conhecem Garopaba, bem como realizamos observações de campo. Observamos que a importância do ensino de geografia na leitura do patrimônio pode fomentar a contestação das formas agendadas, indo além do discurso descomprometido dos espaços racionais de turismo, bem como descobrir em primeira mão as pré-concepções que nos vendem dos destinos turísticos. $O$ ensino de geografia de qualidade, que estude as paisagens a partir de suas gêneses, favorece a leitura valorativa do patrimônio material e imaterial que compõem os diferentes lugares.
\end{abstract}

PALAVRAS-CHAVE: Turismo; Ensino de Geografia; Garopaba; Paisagem e Lugar.

\section{ABSTRACT}

The text presents a research about the relationship between tourism and geography, considering the role of teaching of geography in the reading of local patrimony. Placed in Garopaba, a town in the coast of Santa Catarina (Brazil), it aims at discovering, temporarily, the importance of the teaching of geography in the construction of the touristic space. For a better comprehension, we have used concepts from geography as well as from the social representation involved in the reading of landscape and the construction of the place. The method used was the complexity one. Through qualitative research, we have done narrated episodic interviews with tourists, locals and geography teachers, and made field observation. We have realized that the teaching of geography is important to the reading of patrimony as it allows a critical view over pre-established forms, helping to go beyond the uncommitted rational discourses of touristic places, as well as to discover the pre-conceptions that are sold about touristic spots. The teaching of high-quality geography, one that analyses landscape through its genesis, facilitates valuable readings of material and immaterial patrimonies that are found in different places.

KEYWORDS: Tourism; Geography Teaching; Garopaba; Place and Landscape. 


\section{Introdução}

A Geografia estuda o espaço geográfico. Compreendemos, nesse momento, que o Turismo, em um movimento tanto retroalimentar quanto recursivo, (re)produz o espaço geográfico na sua complexidade. A interface do Turismo e da Geografia nos parece que se estabelece tanto pelas alterações objetivas que incita quanto por sua mediação simbólica na relação dos sujeitos com o espaço. Seus produtos concretos influenciam o modo como um lugar se articula com outros e com a ordem global. Em suas relações costuma instituir valores e significados para os lugares e para 0 patrimônio local, e nortear a estética a ser apreciada e consumida de suas paisagens.

Nesse universo tende a haver uma relação indissociável que se refere a nossa visão de mundo. Os significados que damos às nossas experiências sociais e individuais são conjugados no espaço-tempo que vivemos e costumam ser potencializados pelos valores de sua época, que na sociedade ocidental atual, tendem a estar em si mesmos imbricados com as imagens que a comunicação simula. Uma vez que essa comunicação tem o poder de atualizar valores, fluxos e fixos, conhecimentos e representações sociais nos espaços cotidianos e também nos turísticos, pensamos nas contribuições do Ensino de Geografia para o entendimento, provisório, desses processos. O Ensino de Geografia ao fomentar a leitura e a compreensão do patrimônio, a partir de sua identidade, indo além do que é veiculado na comunicação, habitualmente, de forma superficial, pensamos que pode enriquecer o estarser turista, bem como o ser-estar da comunidade receptora.

$O$ estudo que realizamos, com o intuito de investigar a relação do Turismo com o Ensino de Geografia, teve como guia o método do Paradigma da Complexidade (MORIN, 2000a), onde procuramos reunir significados relativos ao lugar turístico, sua paisagem, ao Ensino de Geografia e das representações sociais, colocando-os em diálogo para que possam remeter uns aos outros no contexto em que se localizam. Pensamos que dessa forma temos uma dinâmica retroalimentar, que visa ser produtiva, no intuito de compreender o espaço turístico. Partimos das questões: A leitura da paisagem interfere na relação do sujeito turista com o local? É possível o turista se lugarizar, ou seja, os turistas construírem laços de afeto com o local visitado que os levem a querer conhecer e cuidar de seu patrimônio? Qual a relação do Turismo com o Ensino de Geografia nesse contexto?

Para responder essas nossas questões, utilizamos a metodologia da pesquisa qualitativa (FLICK, 2009), com a técnica das entrevistas episódicas e das observações de campo. Com esses procedimentos levantamos e analisamos as noções de espacialidade e temporalidade na leitura da paisagem, verificamos se os conhecimentos geográficos aparecem e qualificam ou não essa leitura, as representações sociais e ideológicas inseridas nos olhares de quem lê, e ainda se essa leitura está associada às possibilidades dos sujeitos turistas se lugarizarem. Quiçá, também ponderamos que ao aprendermos e nos envolver com o patrimônio dos locais visitados, em um espiral retroativo, vamos cuidar do patrimônio do nosso local de origem.

A pesquisa foi realizada no município de Garopaba, situado no litoral 
catarinense (Figura 1). Considerando que Garopaba é um destino turístico frequentado por diferentes grupos de interesse, focamos nosso olhar para os turistas e moradores que participam do Turismo Litorâneo, ambientado nas praias, para os sujeitos professores do Ensino de Geografia nas escolas da rede pública loca, pela relação da pesquisa com o Ensino, e com sujeitos que não conhecem o município, para a investigação das representações sociais.

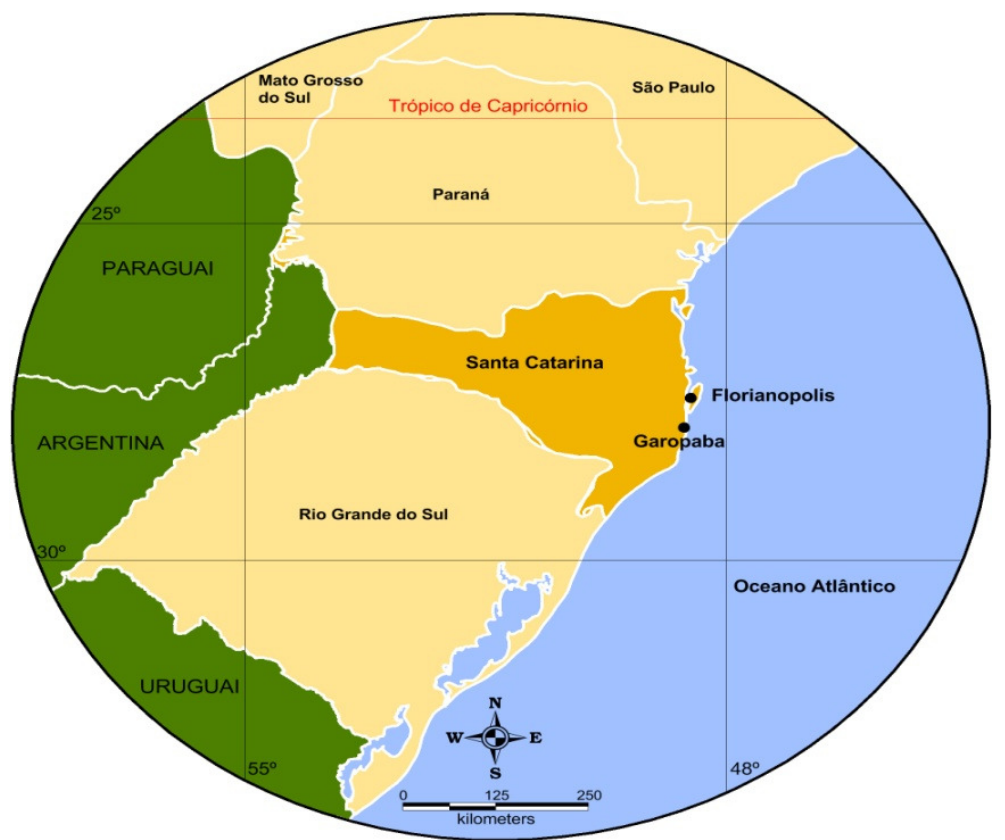

Figura 1. Mapa de localização de Garopaba (SC). Fonte: Elaborado pelos autores. Figure 1. Location map for Garopaba (SC, Brazil). Source: Authors.

\section{O lugar turístico Garopaba: nas ondas do mar}

O lugar turístico Garopaba apresenta um patrimônio natural e cultural próprio por sua localização. Garopaba é especialmente reconhecida por suas praias, pelo surf e atualmente, também, pelo Turismo de observação de baleia. Há grande atratividade, uma vez que o Turismo de praia e mar é um dos destinos mais valorizados nas representações sociais. "[...] a natureza, em especial o litoral, é o recurso turístico mais explorado pelo capitalismo a partir da segunda metade deste século" (RODRIGUES, 1999, p.113).

O município também se incorpora para além do mar. Interiorizando há áreas rurais com um cotidiano bastante diferenciado do da cidade. Atrativos turísticos culturais e históricos, como alambiques, engenhos de cana e de farinha, e atrativos naturais com cachoeiras e mirantes potencializam esse espaço.

O Turismo no município tem sua história associada à mídia. Parece ser a comunicação construindo o espaço turístico. Em 1964, o navio Mercante Brasil Mar, encalha em uma das praias locais, e as manchetes dos jornais, estaduais e nacionais, divulgavam o fato e a praia. Em 1966, um fotógrafo gaúcho é contratado para registrar as obras públicas do município financiadas pelo estado. O fotógrafo retorna outras vezes acompanhado de amigos jornalistas, que juntos, veiculam reportagens de Garopaba em jornais do Rio 
Grande do Sul, alavancando mais o município como destino turístico. (BITENCOURT, 2003).

Muitos dos turistas que vêm a Garopaba começam a comprar terrenos e construir casas para veraneio. "Por sua vez, a vilegiatura marítima intensifica o processo de incorporação da zona de praia à tessitura urbana" (DANTAS, 2009, p.47). A rápida valorização imobiliária traz uma grande circulação econômica e no curto espaço de tempo, entre a chegada da energia elétrica em 1966 e o asfalto em 1986, 60\% de Garopaba já não pertencia aos seus moradores.

As influências do Turismo na cidade são diversas, extrapolam as questões de urbanização, econômicas e políticas. Enquanto um fenômeno complexo, toca nos costumes e nas maneiras de se relacionar com 0 ambiente. O mar, lugar de colheita do alimento, da economia, do desenvolvimento, das baleias, dos deslocamentos marítimos, do refrescar, passa a colher mais um fator desencadeante de desenvolvimento do espaço: os movimentos turísticos.

\section{A complexidade do turismo no espaço geográfico}

O fenômeno do Turismo parece ser complexo, portanto, um tecido que une o social, o cultural, o múltiplo, o fluido em suas fronteiras, tanto as políticas quanto as pessoais, e o fixo em suas estruturas produzidas para o consumo do visitante e para o desenvolvimento econômico (e algumas vezes social) da população que recebe.

Ao pensarmos nas relações que podem emergir desse tecido, quando compreendemos que complexo é, baseado em Morin (2000a, p.31), "o que se tece junto", situamos a atividade turística e suas interações em um princípio dialógico, que busca distinguir para unir o que é (ou parece) contraditório: o particular e o universal, o sujeito e a sociedade, a razão e a emoção, o tempo e o espaço. Ponderamos, por tanto, que fazer uma reflexão do fenômeno turístico em sua complexidade é estar ciente dessas tensões e das retroalimentações que suas relações engendram.

Acreditamos, nesse momento, que o espaço é rico por seus variados movimentos, que se lançam em distintas direções, mas que se complementam também pela dialogicidade que é a vida, tal qual a compreendemos/vivemos.

$\mathrm{Na}$ atualidade da dita globalização, a relação local - global, e sua recursividade, se adensa, em muito, pelas informações, que parecem não parar de chegar de forma intensificada e trazendo a provisoriedade das verdades, também um princípio da Complexidade.

A informação veiculada nas redes tem a tendência de estruturar as relações que representam nossa sociedade atual. Essas redes, cada vez mais intencionais e alargadas, parecem coabitar e ligar as paragens mais distantes, direcionando os locais para suas lógicas hegemônicas, acompanhadas pelas representações sociais que se intensificam ao se comunicar e atravessam as fronteiras. 
Com essa dinâmica, muitas vezes nos sentimos muito próximos uns dos outros, e em contato com as informações e modas globais, proporcionando que o espaço alcance aspectos mais variados na vida social e o cotidiano dos sujeitos se enriqueça, ao mesmo tempo em que se dilui. Parece-nos que essas redes que nos conectam ao mundo e ao outro, acaba por nós afastar, um tanto, de nós mesmo, talvez pela avalanche de dados que ocupam um espaço antes destinado à existência no cotidiano compartilhado das relações sensíveis ${ }^{1}$. Essas relações sensíveis também ocupam e significam nossas identidades, que (trans) formam o espaço, que valoram nosso patrimônio e as paisagens de cada sujeito.

O Turismo, para nós, parece ser uma atividade que pode promover encontros mais sensíveis, uma vez que o turista se desloca até outro local, comunica-se nesse local visitado, o que abre possibilidades para conhecer outros sujeitos, interagir, descobrir (-se). Pensamos que o Turismo pode nos colocar em um movimento de descoberta do outro e de nós mesmo, pois sabemos que nos conhecemos na alteridade, assim como podemos conhecer nosso lugar ao conhecer outros patrimônios.

Compreendemos, nesse momento, que o Turismo se constitui em encontros. Encontros, parece-nos, envolvem prioritariamente deslocamentos e comunicação, que despertam intencionalidades, desejos e fantasias, conhecimentos (geográficos) e representações sociais. Envolvem também uma composição estética do sujeito e do lugar para estar-ser nesse encontro. Pensamos que os encontros do Turismo são do tempo presente, como os eventos, que ao acontecer marca o espaço, e é simultaneamente uma matriz temporal e espacial.

Assim, consideramos significativo para a análise complexa do Turismo as relações/interações entre os sujeitos e desses com o espaço geográfico. As interações, harmônicas ou não, que se estabelecem nos possíveis encontros e desencontros, tendem a sustentar formas materiais e simbólicas em múltiplas representações e imaginários, que constituem também os patrimônios culturais de cada local. São essas relações promovidas pelo Turismo que tomam o foco do nosso estudo ao querer tecer com o Ensino de Geografia.

[...] no turismo, como em outras faixas da cultura, o que está em pauta, em última análise, não são bens, sentidos e valores. São as relações entre os homens. O tipo de turismo que propusermos e praticarmos dependerá do tipo de relações que julgamos aceitáveis e desejáveis entre os homens, isto é, do modelo de sociedade pelo qual optamos (MENESES, 1999, p.99).

No entanto, temos observado, em nossas experiências profissionais com o Turismo, que esses encontros muitas vezes não são qualificados para ampararem relações saudáveis entre os turistas e os sujeitos do local visitado, para que gerem conhecimentos, descobertas, enriquecimentos, valorizações patrimoniais, identitárias e paisagísticas, e até, para um mundo melhor. 
Afinal o que queremos com o Ensino de Geografia, com a educação? $\mathrm{O}$ que queremos com nossas pesquisas, trabalhos, reflexões? Essas questões terão diferentes respostas, tantas quantas forem os sujeitos a ponderarem, mas pensamos que parte significativa das respostas se voltará para um mundo melhor e que nos conduza a uma consciência planetária (MORIN, 2000b) $)^{2}$.

Acreditamos que a perspectiva da consciência planetária toca no que cada um de nós pode fazer, nossas responsabilidades, nossas compreensões, nossa postura diante do mundo e nossos valores sociais. Pensamos que para atuarmos de forma reflexiva e crítica, sendo sujeito cidadão, precisamos conhecer e sermos capazes de interpretar o mundo, de identificar os movimentos do/no espaço.

A Geografia Cultural mostra que participamos de um duplo sistema de distâncias: a do espaço físico e dos espaços psicológicos (CLAVAL, 1999). O espaço, enquanto tecido físico, pode ser transposto pelos deslocamentos, pela comunicação, pelas técnicas atuais cada vez mais especializadas. Já o espaço psicológico parece ser alargado ou aproximado pelas semelhanças dos sistemas e patrimônios culturais quando esses se encontram.

Quando temos a chance do diálogo pelo encontro ou pela comunicação, podemos descobrir que o que nos aproxima tende a ser "infinitamente maior do que aquilo que nos coloca em oposição - o que abre caminho para reinterpretações dos sistemas simbólicos" (CLAVAL, 1999, p.72).

O Turismo pode incentivar esse estreitamento da distância em ambos os espaços: no físico e no psicológico, por inserir sujeitos de diferentes grupos em uma rede de contato. Com isso, temos que o espaço turístico é o local de encontros de sujeitos, desses entre si e desses com a comunidade local e seu patrimônio.

A aproximação parece-nos ser importante para revisar escalas de valores, colocá-las em dúvida, para vivenciar as diferenças, para compreender o outro. Pensamos que construímos nosso espaço a partir de comparações sociais que aceitamos, adaptamos ou rejeitamos. Parece-nos que não podemos compreender nosso mundo interior sem a articulação com a vida social.

Inserimos a importância do Ensino de Geografia por fomentar nesses encontros turísticos, com uma leitura das paisagens em sua gênese e suas transformações contextualizadas, a contestação das formas agendadas, indo além do discurso descomprometido dos espaços racionais de Turismo, bem como questionando no intuito de descobrir em primeira mão as préconcepções que nos vendem dos destinos turísticos quando estamos turistas. Pensamos, que talvez, com uma leitura complexa do patrimônio material e imaterial, o turista possa encontrar seus caminhos que promovam a lugarização.

O Ensino de Geografia também tem realçado seu papel para a população que se organiza e recebe os turistas, para que esses possam conhecer seu lugar e se conhecerem, suas identidades e seus patrimônios, discutir transversalmente o que é o Turismo a fim de, mesmo que 
provisoriamente, compreendê-lo e compreender as articulações que engendra no espaço de cada um e de todos.

\section{A paisagem geográfica para o lugar do turista}

Acreditamos que ler a paisagem é "muito mais complexo do que ver e perceber a paisagem. Envolve uma visão de mundo, consciente $e$ inconsciente, sempre subjetiva e permeada pelo imaginário" (CASTROGIOVANNI, 2003, p.47). Pensamos que nossa leitura da paisagem é uma construção contínua social e particular, onde se sobrepõem conhecimentos, representações e sentimentos.

Por esse conteúdo misto, as lembranças e conhecimentos de Geografia também estão contidos no olhar de quem lê a paisagem. A paisagem em sua complexidade apresenta dialógicas imbricadas no fenômeno de sua conceitualização, de sua contemplação e de seu aspecto relacional: forma - conteúdo; objetivo - subjetivo; realidade - representação. Tais dicotomias permanecem em contato retroalimentar, sem que uma aniquile ou empobreça o olhar sobre a outra, pois constituem uma totalidade dialógica que cria a própria existência, aproximando o espaço vivido do percebido, o científico da emoção.

Nessa compreensão de paisagem abarcamos que o patrimônio cultural, material e imaterial, tanto faz parte como dota de significado a paisagem. O patrimônio cultural, relacionado ao Turismo, que compreendemos em seu referencial associado à identidade de um local, parece assumir significado quando incorporado pelos sujeitos em suas compreensões e interações socioculturais.

Pensamos, nesse momento, que o que caracteriza a cultura parece ser a continuidade de seu processo, assim como os valores que instituímos às paisagens, construída e combinada entre os sujeitos de uma sociedade. A construção parece ser infinita, pois sugerimos que nós, enquanto sujeitos, também somos paisagens, e, como toda paisagem, somos inacabados. Por combinada, queremos nos remeter ao conceito de cultura que se assemelha das representações sociais, que se formam e se fortificam no senso comum, ao ganharem corpo informalmente nas verdades comunicadas entre os sujeitos.

As representações sociais são designadas por Moscovici (2003) como uma "atmosfera" que envolve uma sociedade, permitindo a continuidade da comunicação e organizando o mundo comum. São conjuntos de saberes sociais, proposições elaboradas e compartilhadas socialmente, que habitam o cotidiano de cada um, pois são geradas na vida social e propagadas pela comunicação.

Aprendemos as representações sociais, assim como a cultura parece se estabelecer em um grupo, a partir do nosso convívio social, ainda na fase infantil, e vamos transmitindo o imprinting culturaß ${ }^{\beta}$ de geração em geração, verdadeiros no momento, até que haja uma ruptura na nossa visão da realidade comum. 
Acreditamos, nesse momento, que as representações sociais são parte constituinte da lógica do Turismo, do patrimônio de um local e do espaço geográfico. Por serem construções sociais edificadas a partir do senso comum, são facilmente corporificadas e passam a interferir nos comportamentos dos sujeitos, na construção do conhecimento, nas leituras espaciais que realizamos e nos valores dos patrimônios que significamos.

Pensamos que escolhemos em grande parte os destinos turísticos a partir de representações sociais e de ideologias, tendo nos meios de comunicação um dos principais canais de sua propagação, bem como tendemos a ler e nos identificar ou não com o patrimônio local com essas premissas.

Produzir imagens que criam o desejo e que podem ser consumidas parece estar no cerne do Turismo enquanto um fenômeno também comunicacional. Gastal (2003) chama a atividade turística de Indústria dos Signos, por estar calcada nessa comercialização e no consumo do simbólico e do concreto.

Confiamos, provisoriamente, que o universo de cada um tende a ser limitado ou ampliado pelos seus conhecimentos, princípios, representações e cultura. Assim, os turistas, para explorarem novos ambientes e outros patrimônios, o fazem baseados na esfera cultural e cognitiva que lhe é acessível.

A globalização, que promove a rede de informações, também é subsidiada pelas oportunidades de encontros gerados no seio da atividade turística, assim como sustenta a atividade com seus patrimônios e suas representações sociais, racionalizadas e desterritorializadas. Pois, "o Turismo não é exógeno à sociedade, ele também representa a própria sociedade" (CASTROGIOVANNI, 2004, p.114)

Essa globalização da circulação e dos agendamentos parece também nos inserir nas representações pré-concebidas dos espaços turísticos. Um conjunto de imagens e expressões é oferecido antes da viagem realizada. Está presente aí a ideia de uma anterioridade, entre o que vai ser vivido e o que acaba sendo experimentado de fato na viagem turística. Assim, a viagem turística e a necessidade de consumo do destino começariam bem antes do embarque.

Acreditamos, neste momento, que a Comunicação procura agendar uma Cultura turística de consumo para certos Lugares. Em outras palavras, parece que ocorre a manipulação do Espaço Geográfico, através de um discurso, que encaminha para a necessidade de consumo de um Lugar (CASTROGIOVANNI, 2004, p.45).

Esses agendamentos configuram em representações sociais, uma vez que são assumidas socialmente. Assim, o Turismo parece estar sobremaneira baseado em um conjunto de pré-concepções e concepções de valores e imagens de valor cultural. Conforme Garcia e Oliveira Neto (2006, p.8), indicam que "isso se dá pelo fato do homem ser um ser simbólico. $A$ relação do homem com o mundo, com o trabalho, com o lazer é sempre 
revestida de significações e valorizações e com o Turismo não poderia ser diferente". Moscovici (2003) alerta que, a partir das representações sociais, julgamos e criamos uma imagem das pessoas e dos objetos antes mesmo de estabelecermos uma relação com eles. Criamos sonhos, imaginários. Nesse sentido, temos a tendência de querer confirmar essa imagem e nossas informações costumam ser deturpadas a partir do julgamento prévio.

As experiências vividas, tanto pelos sujeitos turistas como pelos atores locais do Turismo, por mais diversas que sejam, pensamos que trazem as imposições dessa cultura hegemônica agregada. Por isso, também ponderamos a complexidade do Turismo nas representações sociais associadas ao evento, onde, vemos provisoriamente que, no contexto atual tecem sentimentos e ambições para a busca de algo que parece nos retroalimenta por sua ideologia de status social, de conhecimento intelectual e de recarregar as energias. Essa prática parece ter intrincada a relação espacial da atividade turística, na medida em que variam seus reflexos no contexto relacional do local/global.

É nesse sentido, que entendemos que o Turismo produzido entre o movimento da sociedade e a sensibilidade do espaço vivido traz um comportamento implícito em sua dinâmica.

Se as pessoas não viajarem, elas perdem o status. A viagem é a marca de um status. É um elemento crucial, na vida moderna, sentir que a viagem e as férias são necessárias. Preciso tirar umas férias: eis a mais segura reflexão de um discurso moderno. (URRY, 2001, p. 20).

O status social que o estar-ser turista proporciona, entendemos que é uma representação social. Outras autoras reforçam esse entendimento, como Moesch (2000, p. 15) ao destacar que "é algo que confere status, distinção. É um bem cultural". Rodrigues (1999, p.26) atesta que "a necessidade imperiosa de viajar é fabricada, sendo incorporada mercadologicamente ao rol de necessidades básicas do homem. [...] É o Homo turisticus ou Homo viajor". Por acreditarmos que essa é uma representação social produzida no cerne das redes hegemônicas, conceituamos como ideológicas (THOMPSON, 1995).

Por que tiramos fotos quando viajamos? Por que costumamos visitar os mesmos locais que nossos amigos, familiares, conhecidos visitaram e que os guias turísticos indicam? Por que, em muitos casos, tiramos fotos apenas do que o guia de turismo nos aponta? "Turismo parece ser uma forma de condicionamento, de utilização do espaço e da temporalidade" (CASTROGIOVANNI, 2004, p.35).

Pensamos, por essas questões do nosso período atual, que cada vez mais falta a habilidade de analisar, de refletir e de interagir em um ato sensível, com suas informações e conhecimentos do mundo. Os agendamentos da comunicação tendem a potencializar as representações sociais, principalmente as hegemônicas, que contribuem para esse modo institucionalizado de nos relacionarmos e estarmos no mundo. Nesse sentido, muitas vezes, os meios de comunicação concretizam ideias, imagens, 
sentimentos e comportamentos, que limitam as possibilidades de outros arranjos em nossas ações.

A realidade empírica tende a estar impregnada de valorizações e significações atribuídas pelos sujeitos em seu cotidiano e em seus eventos. Todo ambiente que envolve o homem seja físico, social, cultural ou imaginário, parece influenciar sua conduta. A prática turística pelos seus movimentos que provocam (des)encontros parece requisitar que os sujeitos e as coletividades aproximados saibam entender as lógicas do Turismo e dos espaços.

A educação geográfica talvez possa nos dar a base para que essa aproximação seja qualificada na construção dos nossos mundos interiores a fim de que sejam questionadores da realidade apresentada, fortes em seus processos identitários criativos para a interação com os diferentes e solidários com os outros mundos, pois, como traz Claval (1999, p.69), "a abordagem cultural sublinha, como mostrou Augustin Berque (1990), que a construção dos indivíduos e das coletividades se efetua em ambiente que ele deve compreender e interpretar".

Parece-nos que quando os turistas não têm uma leitura espacial enriquecida ficam muito suscetíveis aos agendamentos da mídia e às representações sociais ideológicas, o que levariam a não compreenderem o patrimônio e sua paisagem no local visitado e comprometerem a sua lugarização. A distância do espaço psicológico, conceituado pela Geografia Cultural, parece ser ampliada nessas situações.

\section{A lugarização do turista para o respeito com os patrimônios}

Compreendemos, nesse momento, que o lugar de um sujeito é o seu ninho, tecido por vínculos afetivos é um local de referência cultural, de identidade e de carinho individual. Aninhados no lugar concreto, nos sentimos acolhidos, o dotamos de significado em uma construção mediada pela intimidade, em que a materialidade do lugar é enlaçada simbolicamente com imaterialidades.

O espaço tende a transformar-se em lugar à medida que é vivido e significado por um sujeito e/ou por um coletivo, adquirindo personalidade e identidade. Portanto, parece-nos que o lugar deve ser apreendido como movimento de relações nas quais os próprios lugares vão se (des)(re)fazendo e significando seus patrimônios.

Com isso, temos que a percepção, o histórico, os patrimônios por ele reconhecidos e os conhecimentos de cada sujeito, por meio da experiência subjetiva e na intersubjetiva constroem o lugar. Em decorrência, acreditamos, nesse momento, que o sentido e o sentimento que o sujeito recobre seu lugar pode se propagar também nas demais leituras do espaço. O sujeito parte de seu lugar para interpretar o mundo, ler o espaço e suas paisagens. "É $O$ espaço, isto é, os lugares, que realizam e revelam o mundo, tornando-o historicizado e geografizado, isto é, empiricizado" (SANTOS, 2010, p.112).

Nesse contexto, para nós, o lugar também é complexo, dialogicamente construído entre o local e o global, entre solidariedades e 
racionalidades $^{4}$, que se realizam por aproximação, associação e/ou por conflito. Pensamos que o cotidiano local tem dinâmica própria, que filtra, maximiza ou minimiza as influências e solicitudes globais, mas que tende as enriquecer porque adiciona sua cultura. "O lugar é o cotidiano das ordens globais e das paixões locais" (SANTOS, 2008, p.322), cheias de criatividade e de incertezas, pois a solidariedade é fruto da diversidade e que não exclui a surpresa.

Compreender o lugar parece ser aproximar-se da história e da Geografia, da memória social e individual, dos seus patrimônios, contextualizar o acontecer em um tempo e um espaço cotidiano e por sua localização no conjunto do espaço-mundo. Com Santos (2008), indicamos que nessa época da fluidez precisamos redescobrir o lugar com seus novos significados e sua história patrimonial. Entendemos que o Turismo é uma das dimensões atuais de muitos lugares.

Os Sujeitos, ao viverem o Espaço Turístico, o (re) constrói através de múltiplos 'pertencimentos'. Esta relação de 'pertencimento' lugariza o espaço e, parece que assim, vai sendo construído o que entendemos por Lugar turístico, ou não? O Lugar turístico teria mais densidade de pertencimento, de sentimento em constituir o espaço do que o Entre-Lugar turístico (CASTROGIOVANNI, 2004, p. 177, grifos do autor).

Trabalhamos nessa pesquisa também o conceito de entre-lugar, apoiado em Castrogiovanni (2004). Se o lugar é nosso ninho, o entre-lugar seria aquele voo em que pousamos em algum local, mas não nos apropriamos do espaço, porque não nos colocamos em um movimento de integração com o meio. Entendemos que o entre-lugar turístico é onde 0 turista pode ser visto e ver, em menção ao Turismo como moda e de status social, pois no lugar turístico ele extrapola com essas aparências. Há outra afinidade com lugar, que vai além da sua superfície estética.

A preposição entre, usada em complemento a lugar, referencia a passagem pelos locais. Nessa passagem, também produz encontros tecendo pontos de interconexão, mas esses pontos tendem a ser pouco sólidos, não sustentando uma rede de trocas, uma rede de transformações autônomas e coletivas, não havendo uma compreensão do patrimônio local. Já o lugar turístico parece ser revelador de relações significativas, é onde realizamos o outro através de nós, em bases ricas espacialmente, que nos proporciona não nos confundirmos com o outro e delimitarmos nossa esfera, mesmo que com fronteiras fluidas, para que a partir dela possamos entender a trama complexa do espaço.

O entre-lugar é o espaço onde, na relação com o outro, o lugar do outro é negociado e assimilado ao meu, sem que haja a efetivação da ancoragem e da objetivação desse lugar, e assim ficamos restritos a suas representações e aos imaginários coletivos. 
O espaço turístico parece ser tecido pelos movimentos momentâneos de sujeitos imbuídos de representações sociais, que mobilizam interrelações plurais, produzindo os (entre) lugares no local visitado. Nesse contexto, os sujeitos turistas potencializam comportamentos em si e nos outros, que são tanto possibilitadores da (entre) lugarização do turista, a partir do espaço vivido e apreendido, quanto de certa estranheza (positiva e negativa) do nativo para seu próprio lugar, que recorrentemente coloca em xeque sua identidade e seus patrimônios.

Pensamos que a identidade parece não se referir a uma essência permanente, mas a situações e interesses movediços, assim como as paisagens. Acreditamos que para uma população a sua identidade é questão de referência, é onde nos apoiamos quando estamos em frente ao outro.

Identificar, no âmbito humano-social, é sempre identificar-se, um processo reflexivo, portanto, e identificar-se é sempre um processo de identificar-se com, ou seja, é sempre um processo relacional, dialógico, inserido numa relação social. Além disso, como não encaramos a identidade como algo dado, definido de forma clara, mas como um movimento, trata-se sempre de uma identificação em curso, e por estar sempre em processo/ relação ela nunca é una, mas múltipla. Toda identidade só se define em relação a outras identidades, numa relação complexa de escalas territoriais e valorações negativas e positivas (HAESBAERT, 1999, p.174-5).

Refletimos que é importante teorizar esse universo de sonhos, não para que perca sua magia, até porque "a importância da fantasia e do imaginário no ser humano é inimaginável" (MORIN, 2000b, p. 21), mas para que possa ser mais significativo no estar-ser do turista e da comunidade receptora. Parece haver uma enorme distância entre o real e o imaginário, mas que se aproximam pelos (des) encontros turísticos, nas ações dos sujeitos turistas, as quais repercutem na localidade que os recebe, em seus patrimônios e em seus habitantes, repercutem em si e na sociedade em que esse sujeito turista está inserido no cotidiano. Supomos que o Turismo concretiza no espaço geográfico, seus movimentos engajados de representações simbólicas, no corpo e nos sonhos de cada sujeito.

\section{Resultados provisórios: o lugar e a indentidade no turismo}

Sugerimos, diante das análises realizadas do nosso estudo localizado em Garopaba, que os entre-lugares se estabelecem tanto para os moradores quanto para os visitantes quando esses não conseguem negociar seus espaços, por terem suas estruturas identitárias frágeis, suas leituras de paisagem superficiais e quando comparam os seus lugares, seus patrimônios com os dos outros locais, assumem papel de inferioridade/superioridade social por inseguranças.

Compreendemos, nesse momento, que o Ensino da Geografia deve valorizar as diversidades culturais e os patrimônios materiais e imateriais, e 
para tal acreditamos ser importante compreender a história, a cultura, os patrimônios e a identidade do seu lugar. Se não temos nossas bases identitárias sólidas, tendemos a ver o outro em superioridade e/ou como um invasor, no caso dos turistas.

Com o intuito da busca pela lugarização do sujeito turista, por entendermos nesse momento, que quando nos lugarizamos, nossas relações com o lugar e seu patrimônio são de cuidado e de apreço, porque também passamos a fazer parte do lugar, fica a percepção de que o turista pode se lugarizar. No entanto, sabemos que os caminhos para a lugarização turística são tantos quantos os sujeitos que se inserem no movimento dos encontros do Turismo e do Ensino de Geografia.

Para um sujeito se lugarizar, parece-nos haver a tendência da necessidade de conhecer o local, de nos relacionarmos a fim de desvendar suas confidências, a construção e os significados de seus patrimônios e de suas paisagens, um tempo lento de momentos compartilhados consigo, com os outros, com o espaço e, ainda, que é preciso a contrapartida local na mesma dimensão que prescinde de referências espaciais, indo além das racionalidades.

Para a contrapartida local nos remetemos que os sujeitos do destino turístico estejam enriquecidos em conhecimentos que sustentem suas identidades, o que nos encaminha para que seus patrimônios e suas paisagens sejam reconhecidos e compreendidos, para que então seus lugares possam ser negociados com os turistas, oportunizando encontros saudáveis e ricos.

No Turismo, toda a lugarização parece incluir des-re-locamento (sair do lugar, reencontrar um lugar), tocando diretamente aos envolvidos, quem já se encontra no lugar, quem chega, quem ficou no lugar de partida. Isso sugere que há uma intenção na ação e essa ação solicita envolvimento. $O$ deslocamento no Turismo é externo, mas para a lugarização acontecer há, parece-nos que necessariamente, um deslocamento interno, um voltar para si, para sua identidade, ao sair de seu lugar cotidiano.

Além disso, sabemos que o lugar turístico é um lugar onde o turista consegue se territorializar, assim quanto mais sentir o pertencimento do lugar, mas chance deste turista querer voltar para reviver seus encontros.

Para que possamos ler a paisagem precisamos articular as noções relacionadas à temporalidade, à espacialidade e ao Ensino de Geografia, na busca pela internalização da paisagem e dos patrimônios. É preciso tomar a paisagem, o patrimônio e o lugar como inserção do sujeito no mundo, tanto o seu mundo como o compartilhado com os demais.

Ressaltamos a importância da espacialidade nesse processo, em uma vivência com sensibilidade. Parece-nos que o tempo que incorpora significado à paisagem e ao seu lugar é relativo a essa espacialidade, e aqui compreendemos que o tempo de um turista pode ter uma densidade valorativa bem maior do que o tempo, em geral corrido e habitual, do cotidiano. Esse tempo do turista dialoga com o olhar do turista proposto por 
Da Hora e Cavalvanti (2003), como em um tempo metafísico que ganha minutos e horas ao nos abrirmos as pequenas manifestações do novo, que permitem associar a paisagem do patrimônio local à memória afetiva, aos conhecimentos abstraídos e ao mundo vivido.

Associar o Turismo ao Ensino de Geografia pode ser trabalhado dentro dessa concepção de estudar o seu lugar e sua paisagem, seus patrimônios e sua identidade, com um olhar de turista, sob a fruição da estética, e indo além dela, desenvolvendo o sentido de descobrimento, de construção do conhecimento pela observação e contemplação, pela vivência e interação, com prazer e responsabilidade. Por que não ensinar a partir de algo que nos encanta e nos envolve? Compreendemos, seguindo Besse (2006, p.63), que "trata-se de acompanhar, ou de aprofundar, a estética da ciência, como se o conhecimento se colocasse a serviço da fruição".

O Ensino de Geografia e o Turismo, em diálogo, tem o potencial de exercer várias funções: fruição, conhecimento crítico, informação, educação, compreensão, desenvolvimento de vínculos de subjetividade, sonhos, etc. No nosso entendimento, o grande privilégio de pensar sobre essas áreas é poder articular, de preferência solidariamente e transversalmente, a multiplicidade de funções, educacionais, pois cada vez mais encontramos fundamentos para acreditar que o que dá sentido à vida dos lugares são os encontros saudáveis e lugarizados, em suas complexidades.

Pensamos que se quisermos compreender o mundo, compreender os seres vivos e suas possibilidades, sugerimos que temos que olhar, cheirar, tocar, sentir em sua complexidade, na reunião da realidade onde as disciplinas estão indissociavelmente entrelaçadas sem fronteiras demarcadas, na transdisciplinaridade, sem que com isso cada área do conhecimento perda a sua identidade e importância.

Pela nossa experiência profissional e pelas pesquisas que estudamos, vimos que a educação para o Turismo, de forma geral no Brasil, visa dois enfoques: um de capacitar mão de obra para trabalhar com a atividade e outro voltado a educação ambiental, que tem se restringido a lidar com os problemas ambientais tais como lixo, poluição, desmatamento. Nas narrativas dos sujeitos entrevistados que trabalham com o Ensino de Geografia em Garopaba, verificamos que o mar, a praia e o Turismo não figuram enquanto temas desenvolvidos nas escolas em suas relações transversais e espaciais com os sujeitos habitantes. Parece-nos que as escolas locais ainda não se atentaram para que o Turismo é cada vez mais a paisagem cotidiana de seus lugares, assim como é de muitos lugares brasileiros.

Por esse contexto, acreditamos que educar para o estar-ser turista, para a lugarização, para a leitura do patrimônio, e assim também para a vida, ainda é uma lacuna. $E$ pensamos que a educação pode trazer também essa indicação na caminhada da vida. 


\section{Referências bibliográficas}

BESSE, J-M. Ver a Terra: seis ensaios sobre a paisagem e a geografia. São Paulo: Perspectiva, 2006.

BITENCOURT, F. De Ygara-Mpaba a Garopaba: Sete mil anos de história. Garopaba: Gráfica São Joaquim de Garopaba, 2003.

CASTROGIOVANNI, A.C. Turismo e Espaço: reflexões necessárias na pósmodernidade. In GASTAL, S.; CASTROGIOVANNI, A.C. (ORGS). Turismo na pós-modernidade (des) inquietações. Porto Alegre: EDIPUCRS, 2003.

CASTROGIOVANNI, A.C. A geografia do espaço turístico, como construção complexa da comunicação. 2004. 335 f. Tese (Doutorado em Comunicação Social), Curso de Pós-Graduação de Comunicação Social da Pontifícia Universidade Católica do Rio Grande do Sul, Porto Alegre, 2004.

CLAVAL, P. A geografia cultural: o estado da arte. In: CORREA, R.L.; ROSENDAHL, Z. (Orgs.). Manifestações da cultura no espaço. Rio de Janeiro: EdUERJ, 1999.

DA HORA, A.S.; CAVALCANTI, K.B. Turismo Pedagógico: Conversão e Reconversão do Olhar. In: REJOWSKI, M.; COSTA, B.K. (Orgs.). Turismo Contemporâneo: Desenvolvimento, estratégia e gestão. São Paulo: Atlas, 2003.

DANTAS, E.W.C. Maritimidade nos trópicos: por uma geografia do litoral.

Fortaleza: Edições UFC, 2009.

FLICK, U. Introdução à pesquisa qualitativa. $3^{\text {a }}$ ed. Porto Alegre: Artmed, 2004 / 5 ed. 2009.

GARCIA, D.S.; OLIVEIRA NETO, A.F. Cidades imaginárias: a imagem da cidade e seus elementos. Mercator - Revista de Geografia da UFC, Fortaleza: UFC, ano 05, número 10, 2006.

GASTAL, S. Turismo na Pós-Modernidade: agregando imaginários. In: GASTAL, S.; CASTROGIOVANNI, A. (orgs.) Turismo na pós-modernidade (de) inquietações. Porto Alegre: EDIPUCRS, 2003.

HAESBAERT, R. Identidades Territoriais. In: CORREA, R.L.; ROSENDAHL, Z. (Orgs.). Manifestações da cultura no espaço. Rio de Janeiro: EdUERJ, 1999.

MENESES, U.T.B. Os "usos culturais" da cultura contribuição para uma abordagem crítica das práticas e políticas culturais. In: YAZIGI, E.; CARLOS, A.F.A.; CRUZ, R.C.A. (Orgs). Turismo: espaço, paisagem e cultura. São Paulo: Hucitec, 2 ed, 1999.

MOESCH, M. A produção do saber turístico. São Paulo: Contexto, 2000.

MORIN, E. Da Necessidade de um Pensamento Complexo. In: MARTINS, F.M.; SILVA, J.M. (Orgs). Para Navegar no Século XXI. Porto Alegre: Sulina/EDIPUCRS, 2000a.

MORIN, E. Os Sete Saberes necessários à Educação do Futuro. São Paulo: Cortez/UNESCO, $2^{\underline{a}}$ ed., 2000b. 
MOSCOVICI, S. Representações sociais: investigações em psicologia social. Rio de Janeiro: Vozes, 2003.

RODRIGUES, A.B. Turismo e espaço: rumo a um conhecimento

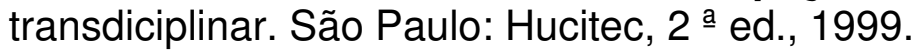

SANTOS, M. A natureza do espaço: técnica e tempo, razão e emoção. São Paulo: Edusp, 4 ed., 2008.

SANTOS, M. Por uma outra globalização: do pensamento único à consciência universal. Rio de Janeiro: Record, 19 ed., 2010.

THOMPSON, J.B. Ideologia e Cultura Moderna: Teoria social crítica na era dos meios de comunicação em massa. Petrópolis: Vozes, 1995.

URRY, J. O olhar do turista: lazer e viagens nas sociedades contemporâneas. São Paulo: Studio Nobel / Sesc, 3ํㅡㄹ. ed., 2001.

2009.

\section{Notas:}

${ }^{1}$ Por relações sensíveis queremos nos remeter as conversas tecidas com simplicidade, com troca de olhares, em que sonhos, acontecimentos ordinários, descobertas, identidades e compreensões são compartilhadas.

2 Com Morin (2000b) aprendemos que a consciência planetária está em reconhecermos nossas identidades individuais ao mesmo tempo que a terrena, para humanizar a humanidade ao compreendermos que todos temos a mesma origem e o mesmo destino, que o Planeta Terra é onde todos habitamos e que depende, em muito, de nós o futuro da vida, tal qual a conhecemos.

${ }^{3}$ Com o imprinting cultural compreendemos um certo conformismo cognitivo em aceitar sem contestar algumas marcas matriarcais, é a normalização das representações sociais que por estarem conosco desde que nos entendemos por sujeitos, são tão corriqueiras que assumimos como verdadeiras. "O imprinting cultural marca os humanos desde o nascimento, primeiro com o selo da cultura familiar, da escolar em seguida, depois prossegue na universidade ou na vida profissional." (MORIN, 2000b, p.28).

${ }^{4}$ Racionalidade nesse texto significa a negação do raciocínio lógico em prol do social. É uma demanda do sistema hegemônico. Já irracional ou contrarracional são movimentos de bases populares, que versam fora da lógica do poder hegemônico. Na visão espaço-social da contemporaneidade percebemos apoiados em Santos (2008), que a racionalidade é a premissa da era globalizada, que impõe a sua racionalidade em objetos que nos cercam e tem parte representativa no domínio de nossas ações. 
Juliane Magagnin da Soller: Universidade Federal do Rio Grande do Sul, Porto Alegre, RS, Brasil.

E-mail: borboletas7@yahoo.com.br

Link para o currículo Lattes: http://lattes.cnpq.br/7056906973810296

Antonio Carlos Castrogiovanni: Universidade Federal do Rio Grande do Sul, Porto Alegre, RS, Brasil.

E-mail: castroge@ig.com.br

Link para o currículo Lattes: http://lattes.cnpq.br/7721027764504488

Data de submissão: 30 de junho de 2012

Data de recebimento de correções: 13 de julho de 2013

Data do aceite: 19 de fevereiro de 2014

Avaliado anonimamente 